\title{
Changes in network connectance and temporal dynamics of gas exchange in Citrus sinensis under different evaporative demands
}

\author{
Gustavo M. Souza ${ }^{*}$, Rafael V. Ribeiro ${ }^{1}$ and Steven M. Pincus ${ }^{2}$
}

${ }^{1}$ Laboratory of Plant Stress Physiology, Dept. Biological Sciences, University of São Paulo - USP, CP 09, 13418-900, Piracicaba, SP, Brazil (Current address: Faculty of Agricultural Sciences, University of Oeste Paulista - UNOESTE Campus II, Rodovia Raposo Tavares km 572, 19067-175, Presidente Prudente, SP, Brazil); ²Guilford, CT, 06437, USA. *Corresponding author: gumaia@universiabrasil.net Received: 20/05/2004, Accepted: 20/11/2004

Stomatal aperture is an essential factor both in regulation of transpiration and net photosynthesis. This regulation is especially important in the response of plants to drought or to an increase in leaf-to-air vapor pressure difference $(V P D)$; however, such a regulation is part of a complex dynamical environment, associated with multiple regulatory pathways. Accordingly, we studied the effects of $V P D$ on gas exchange of Citrus sinensis via the evaluation of two complementary analytic approaches, to approach an understanding of the full scope of the system interactions. First, we used classical statistical methodologies, e.g., means, coefficient of variation, and linear correlation. Second, we used measures developed for more model-independent applications, Approximate Entropy ( $A p E n$ ) to evaluate the irregularity or complexity of gas exchange time-series, and network connectance to evaluate changes in the extent of linkage among specified gas exchange parameters. The analyses of experiments carried out under constant environmental conditions in each $V P D$ treatment (1.0, 2.0 and $3.0 \mathrm{kPa})$ showed a number of relatively subtle results of physiological consequence, such as differences in network connectance during the period of measurements at the same condition showing different patterns of gas exchange regulation. Additionally, VPD changes affect the dynamics of gas exchange by alterations in the irregularity of the time-series. These experiments highlight the endogenous and self-organized mechanisms that underlie the gas exchange process with further theoretical findings and possible practical applications.

Key words: approximate entropy, leaf-to-air vapor pressure difference, network modulation, time-series analysis.

Mudanças na conectância da rede e dinâmica temporal das trocas gasosas em Citrus sinensis sob diferentes demandas evaporativas: A abertura estomática é um fator essencial na regulação da transpiração e fotossíntese. Essa regulação é especialmente importante na resposta das plantas à seca ou ao aumento na diferença de pressão de vapor entre folha e ar $(V P D)$. Tal regulação é parte de um complexo e dinâmico ambiente, sendo associada a múltiplas vias regulatórias. Neste trabalho, estudamos os efeitos do VPD sobre as trocas gasosas de Citrus sinensis mediante duas abordagens analíticas complementares, visando à compreensão das interações no sistema vegetal como um todo. Em primeiro lugar, utilizamos métodos clássicos de estatística, ex. médias, coeficientes de variação e correlação linear. Em seguida, utilizamos a entropia aproximada $(A p E n)$ para avaliar a irregularidade ou complexidade de séries temporais de trocas gasosas, e conectância de rede para avaliar as mudanças nas relações entre parâmetros específicos de trocas gasosas. As análises dos dados coletados sob condições ambientais constantes em cada tratamento de $V P D(1,2$ e $3 \mathrm{kPa})$ mostraram um conjunto de resultados de interesse fisiológico, como diferenças na conectância da rede de trocas gasosas durante o período de medidas na mesma condição de $V P D$, sugerindo diferentes padrões de regulação das trocas gasosas. Além disso, mudanças no $V P D$ afetaram a dinâmica dessas trocas, alterando a irregularidade das séries temporais. Este estudo destacou os mecanismos endógenos e auto-organizados que são subjacentes aos processos de trocas gasosas com interessantes repercussões teóricas e possíveis aplicações práticas.

Palavras-chave: análise de séries temporais, diferença de pressão de vapor entre folha e ar, entropia aproximada, modulação de redes. 


\section{INTRODUCTION}

Stomatal aperture is a determinant factor both in regulation of transpiration and net photosynthesis (Farquhar and Sharkey, 1982; Syvertsen and Lloyd, 1994; Jones, 1998). This regulation is especially important in the response of plants to drought or to an increase in vapor pressure deficit. For example, environmental constraints such as high vapor pressure deficit affect the plant gas exchange behavior, reducing stomatal conductance and then decreasing transpiration and net photosynthesis, for instance, as observed in Citrus spp (Khairi and Hall, 1976; Syvertsen and Lloyd, 1994; Brakke and Allen Jr, 1995; Medina et al., 1999; Veste et al., 2000). Moreover, variations in air humidity lead to changes in the stomatal behavior, disturbing the transpiration and net photosynthesis dynamic (Haefner et al., 1997; Mott and Buckley, 1998). By its rapid response to environmental changes, the control of stomatal opening plays a central role in the regulation of the internal water content, as well as the water use efficiency of plants (Levy, 1980; Jones, 1998).

However, such a regulation cannot be simply represented. Multiple pathways of regulation of stomatal aperture have been identified. They are based on the influence of internal $\mathrm{CO}_{2}$, light intensity, light quality, temperature, air vapor pressure deficit and water (potential) in leaf tissues, PGRs (phytohormone growth regulators) concentration and cell sensitivity, and the biological clock (Farquhar and Sharkey, 1982; Zeiger et al., 1987; Erdei et al., 1998; Jones, 1998). In regard to such a complex reality, regulation of stomatal aperture appears as a highly complicated and multi-faceted process. These characteristics, of course, are hardly restricted to the regulation of stomatal aperture: live beings are typically dynamical non-equilibrium systems influenced by nonlinearities, feedback, composite system features, and time delays (Nicolis and Prigogine, 1977; Hütt and Lüttge, 2002). Thus, it would not be unexpected that classical static measures such as moment statistics might fail to account for the full extent of the interactions that can emerge from the relationship between plants and their environment. In particular, in such a complex dynamical environment, some essential physiological correlates may show most vivid changes in statistics or measures apart from moments or linear correlation, prompting the present study.

According to Amzallag (2001), the effects of environmental disturbances on the gas exchange network may be evaluated through both changes in the variability of network elements and in the strength of the network connectance. It is generally accepted that variations about the average do not have biological significance, they would rather be experimental artifacts. However, there is strong evidence that the variability in biological measurements may have a biological significance (Trewavas, 1986; Green, 1996; Erdei et al., 1998; Amzallag, 1999 and 2001; Hütt and Lüttge, 2002). Changes in the variability level in a given parameter can be analyzed regardless of changes in the mean value of the parameter when the variability is normalized as a variation coefficient (CV) (Amzallag, 2001). The comparisons of $\mathrm{CV}$ values may indicate alterations in the system network, but they do not supply information on the nature of these changes. Thus, Amzallag (2001) suggests connectance evaluation of the network through the analysis of the correlation coefficients normalized. The correlation coefficient is considered not only a test of the significance correlation, but also as a measure of strength of the relationship (connection) between two parameters.

To assess changes in the temporal dynamics of gas exchange parameters, we utilize approximate entropy, $A p E n$, a model-independent statistic defined in Pincus (1991), with further mathematical properties and representative biological applications (Fleisher et al., 1993; Pincus and Singer, 1996; Pincus et al., 1996; Pincus and Kalman, 1997; Pincus and Singer, 1998; Pincus et al., 1998, Souza et al., 2004). Herein, we calculate $A p E n$ for the overall time-series, for each physiological parameter, to assess possible changes in the dynamics of the recorded time-series. ApEn assigns a nonnegative number to a sequence or time-series, with larger values corresponding to greater apparent process randomness or serial irregularity, and smaller values corresponding to more instances of recognizable features or patterns in the data.

Therefore, we characterized physiological responses to $V P D$ changes in three ways. First, we compared the gas exchange parameter (i.e. transpiration, $\mathrm{CO}_{2}$ assimilation, stomatal conductance and intercellular $\mathrm{CO}_{2}$ concentration) averages in order to assess differences in each parameter in response to $V P D$ changes. Second, we evaluated changes in the network composed by the relationships between the gas exchange parameters in order to assess differences in the network relationships as changes in the connectance between paired parameters and in the whole network. Finally, we quantify differences in the regularity of gas exchange temporal dynamics in each parameter to assess subtle changes in the underlying dynamics in response to the different $V P D$ conditions.

As it was the first time that network connectance analysis and $A p E n$ were used together to evaluate the responses of leaf gas exchange to different $V P D$ conditions, some general 
assumptions are needed for subsequent suitable interpretation of the results.

1) The number and strength of the connections among the elements in the network, i.e. connectance, of an organism is directly related to the stability of its system (Trewavas, 1986; Edelman and Gally, 2001).

2) Therefore, a greater connectance, a priori, may achieve higher system stability, although, according to the theoretical analysis of Gardner and Ashby (1970), there is a critical threshold for the system connectance level that could negatively influence the stability of the system. Thus, tighter network connectance could perform a higher level of control system, improving the system capacity to lead with external perturbations.

3) Adaptation is a process of general biological responses (outputs) to environmental stimuli (inputs) in order to enable organismic persistence (Gregorius, 1997).

4) Thus, changes in the system connectance, mostly connectance increases, could be considered as adaptive responses to environmental disturbances.

5) Temporal dynamics with higher irregularity (complexity) could be more efficient under environment constraints because of its intrinsic higher flexibility of response. According to van Voris and O’Neil (1980), Møller et al. (1998) and Souza et al. (2004b) complex dynamics may allow higher stability of biological systems under environmental disturbances, and $A p E n$ can indicate properly changes in the level of complexity in such dynamical systems.

Accordingly, the objective of this study was to use new statistical tools in order to evaluate and quantify changes in gas exchange temporal dynamics of Citrus sinensis submitted to different leaf-to-air vapor pressure differences (VPDs), and changes in the gas exchange network modulation. To this end, we evaluated variations in the level of connection between physiological parameters of gas exchange, and we applied Approximate Entropy $(A p E n)$ to each of the measurement variables considered, as described by Pincus (1991) and Pincus and Singer (1996) in order to quantify the irregularity or complexity of gas exchange time-series.

\section{MATERIAL AND METHODS}

Plant material: The measurements were carried out with 9 months-old sweet orange plants [Citrus sinensis (L.) Osbeck cv. Pera] grafted on 'Rangpur' lime [Citrus limonia (L.) Osbeck], grown in $20 \mathrm{~L}$ plastic pots under natural conditions at Piracicaba, SP, Brazil. Plants were watered until pot saturation daily and fertilized regularly.
Measurements of leaf gas exchange: For the measurements of gas exchange, we used an infrared gas analyzer (LI-6400, LiCor, Lincoln, NE USA) in an open system, with a dewpoint generator (LI-610, LiCor, Lincoln, NE USA) attached in order to improve the leaf-to-air vapor pressure difference $(V P D)$ control. The measurements were done using a $6 \mathrm{~cm}^{2}$ clamp-on leaf cuvette. The LI-6400 was zeroed daily using $\mathrm{H}_{2} \mathrm{O}$ - and $\mathrm{CO}_{2}$-free air. The measurements were done in natural $\mathrm{CO}_{2}$ air concentration (around $360 \mu \mathrm{mol}^{\mathrm{mol}}{ }^{-1}$ ).

On the early morning before measurements the plant of sweet orange 'Pera' was moved to the laboratory and kept well watered. A mature and fully expanded leaf was sealed into the gas exchange chamber in which the desired environmental conditions (temperature, $V P D$ and light intensity) had been pre-adjusted. Leaves were submitted to photosynthetic photon flux density $(P P F D)$ of $800 \mu \mathrm{mol} . \mathrm{m}^{-}$ ${ }^{2} \cdot \mathrm{s}^{-1}$ and maintained at $30^{\circ} \mathrm{C}$ (leaf temperature) in each $V P D$ treatment. $P P F D$ was maintained constant using an artificial quartz halide light source (LI-6400-02 LED light source, LiCor, Lincoln, NE USA) controlled with a quantum sensor located inside the leaf cuvette. Time-series of gas exchange in each VPD treatment, 1.0 (VPD1), 2.0 (VPD2), and 3.0 $\mathrm{kPa}(V P D 3)$, were taken separately on different days. After an early adaptation of $1 \mathrm{~h}$ to each chamber condition, measurements were recorded in each 10 s from 9:00 a.m. to 4:00 p.m. Measurements of leaf gas exchange included: $\mathrm{CO}_{2}$ assimilation $\left(A, \mu \mathrm{mol} \mathrm{CO} \mathrm{CO}_{2} \cdot \mathrm{m}^{-2} \cdot \mathrm{s}^{-1}\right)$, stomatal conductance $(g s$, mol $\left.\mathrm{H}_{2} \mathrm{O} \cdot \mathrm{m}^{-2} \cdot \mathrm{s}^{-1}\right)$, transpiration $\left(E, \mathrm{mmol} \mathrm{H}_{2} \mathrm{O} \cdot \mathrm{m}^{-2} \cdot \mathrm{s}^{-1}\right)$ and intercellular $\mathrm{CO}_{2}$ concentration $\left(\mathrm{Ci}, \mu \mathrm{mol} . \mathrm{mol}^{-1}\right)$. The water use efficiency $\left[W U E, \mu \mathrm{mol} \mathrm{CO} \mathrm{CO}_{2} \cdot\left(\mathrm{mmol} \mathrm{H}_{2} \mathrm{O}\right)^{-1}\right]$ is the result of $A$ normalized by $E$. These measurements were done in the same mature and completely expanded leaf.

Concerning the sources of measurement noises, according to Buckley et al. (1997), we can suppose minimal stomatal heterogeneity effects on gas exchange measurements. Furthermore, the noise in measurements (Pearcy et al., 1989) was evaluated with the empty leaf cuvette. This test showed that the noise due to the LI-6400 was very low ( $<2 \%$ for $A$ and $<0.005 \%$ for $g s$ ) and thus could be presently ignored. The coefficient of variation (total $\mathrm{CV} \%$, which represents the sum of variations of the air flow rate, $\mathrm{CO}_{2}$ and water vapor differentials) of the LI-6400 was around $0.1 \%$ during the measurements. Furthermore, the LI-6400 typically takes new measures every $0.75 \mathrm{~s}$, which is suitable for the baseline time interval used in this study (10 s).

The experiments were performed five times (four times in the same plant and once in a different one), and gave 
qualitatively similar physiological results. All data presented here are from the most representative data set.

Data analysis: Data were submitted to ANOVA and the means of physiological parameters in different $V P D$ s were compared by the Tukey test $(\mathrm{p}<0.05)$.

To assess changes in system network aspects, we evaluated the occurrence of differences in the system modulation of gas exchange when submitted to different $V P D$ s via the concept and measurement of global connectance, $\mathrm{Cg}$ (Amzallag, 2001). Accordingly, to define connectance, first we specify a collection of paired variables of interest in the network. Next, we utilize the correlation coefficients ( $r$ ) between each paired variable not only to test the significance of the correlation, but also as a measure of the strength of the relationship (connection) between the two parameters, by forming the z-transformation: $\mathrm{z}=0.5 \ln [(1+$ r $) /(1-r)]$. Finally, we define the network global connectance $(\mathrm{Cg})$ of the specified collection of paired variables as the average of the absolute z-values calculated above (Amzallag, 2001). In this study, we calculated $C g$ for the following collection of paired variables: $A \times g s, A \times C i, A \times E$, $g s \times E$, and $g s \times C i$, with results displayed in tables 3 and 4 .

The irregularity of the time-series was assessed by $A p E n$. Two input parameters, a run length $m$ and a tolerance window $r$, must be specified to compute $A p E n$. This parameter measures the logarithmic likelihood that runs of patterns that are close (within $r$ ) for $m$ contiguous observations remain close (within the same tolerance width $r$ ) on next incremental comparisons; the precise mathematical definition is given in Appendix. The opposing extremes are perfectly regular sequences, (e.g., sinusoidal behavior, very low $A p E n$ ), and independent sequential processes (very large $A p E n$ ). It is imperative to consider $A p E n(m, r)$ as a family of parameters; comparisons are intended with fixed $m$ and $r$.

When $\mathrm{m}=2$, as is employed herein, we interpret $A p E n$ as a measure of the difference between the probability that runs of length 2 will recur within tolerance $r$ and the probability that runs of length 3 will recur to the same tolerance. A high degree of regularity in the data would imply that a given (matched) run of length 2 would often continue with nearly the same third (next) value, producing a low value of $A p E n$.

ApEn evaluates both dominant and subordinant patterns in data; notably, it will detect changes in underlying episodic behavior not reflected in peak occurrences or amplitudes (Pincus and Keefe, 1992). Additionally, ApEn provides a direct barometer of feedback system change in many coupled systems (Pincus and Keefe, 1992; Pincus, 1994).

$A p E n$ is nearly unaffected by noise of magnitude below $r$, a de facto filter level. ApEn is robust or insensitive to artifacts or outliers: extremely large and small artifacts have small effect on the ApEn calculation, if they occur infrequently. Both these points are evidently useful in clinical and experimental contexts, such as our present setting.

Further technical discussion of mathematical and statistical properties of $A p E n$, including mesh interplay, relative consistency of $(m, r)$ pair choices, asymptotic normality under general assumptions, and error estimation for general processes can be found elsewhere (Pincus and Huang, 1992; Pincus and Goldberger, 1994). To develop a more intuitive, physiological understanding of the $A p E n$ definition, a multistep description of its typical algorithmic implementation, with figures, is developed in Pincus and Goldberger (1994). Moreover, an extended discussion that covers a broad variety of both methodological aspects, plus considerably more background on the physiological meaning and scope of applicability of $A p E n$, can be found in Pincus (2000).

For the studies discussed below, ApEn values were calculated with widely established parameter values of $m=$ 2 , and $r=20 \% \mathrm{SD}$ (standard deviation) of the gas exchange time-series. Normalizing $r$ to each time-series SD in this manner gives $A p E n$ a translation- and scale-invariance (Pincus

Table 1. Mean values and coefficient of variation (CV \%) of the overall time series $(\mathrm{N}=2.200)$ of $\mathrm{CO}_{2}$ assimilation $(A)$, stomatal conductance $(g s)$, intercellular $\mathrm{CO}_{2}$ concentration $(C i)$, transpiration $(E)$ and water use efficiency (WUE) of Citrus sinensis under three leaf-to-air vapor pressure differences $(V P D)$.

\begin{tabular}{|c|c|c|c|c|c|c|c|c|c|c|}
\hline \multirow[t]{2}{*}{$V P D$} & \multicolumn{2}{|c|}{$A\left(\mu \mathrm{mol} \cdot \mathrm{m}^{-2} \cdot \mathrm{s}^{-1}\right)$} & \multicolumn{2}{|c|}{$g s\left(\mathrm{~mol} \cdot \mathrm{m}^{-2} \cdot \mathrm{s}^{-1}\right)$} & \multicolumn{2}{|c|}{$C i\left(\mu \mathrm{mol} \mathrm{mol}^{-1}\right)$} & \multicolumn{2}{|c|}{$E\left(\mathrm{mmol} \cdot \mathrm{m}^{-2} \cdot \mathrm{s}^{-1}\right)$} & \multicolumn{2}{|c|}{$W U E\left(\mu \mathrm{mol} \mathrm{mmol}^{-1}\right)$} \\
\hline & Mean & $\mathrm{CV}$ & Mean & $\mathrm{CV}$ & Mean & $\mathrm{CV}$ & Mean & $\mathrm{CV}$ & Mean & $\mathrm{CV}$ \\
\hline $1 \mathrm{kPa}$ & 2.29 & 21.40 & 0.034 & 20.59 & 235.35 & 6.05 & 0.369 & 20.05 & 6.24 & 13.78 \\
\hline $2 \mathrm{kPa}$ & 2.77 & 22.02 & 0.030 & 20.00 & 189.19 & 6.79 & 0.592 & 17.74 & 4.64 & 6.03 \\
\hline $3 \mathrm{kPa}$ & 1.70 & 34.12 & 0.017 & 23.53 & 193.55 & 12.61 & 0.511 & 25.24 & 3.22 & 14.60 \\
\hline
\end{tabular}


Table 2. Mean values $( \pm \mathrm{SD})$ of the time series $(\mathrm{N}=300)$, by stage, of $\mathrm{CO}_{2}$ assimilation $(A)$, stomatal conductance $(g s)$, intercellular $\mathrm{CO}_{2}$ concentration $(C i)$, transpiration $(E)$ and water use efficiency (WUE) of Citrus sinensis under three leaf-toair vapor pressure differences $(V P D)$.

\begin{tabular}{|c|c|c|c|c|c|c|}
\hline$V P D$ & $\mathrm{St}^{*}$ & $A\left(\mu \mathrm{mol} \cdot \mathrm{m}^{-2} \cdot \mathrm{s}^{-1}\right)$ & $g s\left(\mathrm{~mol} \cdot \mathrm{m}^{-2} \cdot \mathrm{s}^{-1}\right)$ & $C i\left(\mu \mathrm{mol} \cdot \mathrm{mol}^{-1}\right)$ & $E\left(\mathrm{mmol} \cdot \mathrm{m}^{-2} \cdot \mathrm{s}^{-1}\right)$ & $W U E\left(\mu \mathrm{mol} \mathrm{mmol}^{-1}\right)$ \\
\hline \multirow[t]{3}{*}{$1 \mathrm{kPa}$} & A & $2.23 \pm 0.16$ & $0.029 \pm 0.002$ & $227.38 \pm 6.48$ & $0.308 \pm 0.016$ & $7.25 \pm 0.33$ \\
\hline & B & $2.62 \pm 0.11$ & $0.040 \pm 0.001$ & $229.28 \pm 4.06$ & $0.421 \pm 0.006$ & $6.22 \pm 0.28$ \\
\hline & $\mathrm{C}$ & $2.14 \pm 0.06$ & $0.039 \pm 0.001$ & $246.03 \pm 2.09$ & $0.428 \pm 0.005$ & $5.01 \pm 0.13$ \\
\hline \multirow[t]{3}{*}{$2 \mathrm{kPa}$} & A & $2.67 \pm 0.30$ & $0.029 \pm 0.003$ & $190.41 \pm 5.31$ & $0.566 \pm 0.052$ & $4.72 \pm 0.13$ \\
\hline & $\mathrm{B}$ & $3.43 \pm 0.07$ & $0.036 \pm 0.001$ & $181.37 \pm 3.03$ & $0.703 \pm 0.009$ & $4.88 \pm 0.13$ \\
\hline & $\mathrm{C}$ & $2.62 \pm 0.17$ & $0.029 \pm 0.002$ & $185.87 \pm 4.14$ & $0.574 \pm 0.033$ & $4.56 \pm 0.13$ \\
\hline \multirow[t]{3}{*}{$3 \mathrm{kPa}$} & A & $2.01 \pm 0.07$ & $0.019 \pm 0.001$ & $192.55 \pm 7.88$ & $0.586 \pm 0.008$ & $3.44 \pm 0.10$ \\
\hline & B & $2.29 \pm 0.05$ & $0.021 \pm 0.001$ & $171.69 \pm 3.61$ & $0.634 \pm 0.004$ & $3.60 \pm 0.07$ \\
\hline & $\mathrm{C}$ & $1.35 \pm 0.19$ & $0.013 \pm 0.001$ & $189.86 \pm 8.37$ & $0.422 \pm 0.043$ & $3.20 \pm 0.14$ \\
\hline
\end{tabular}

*Time series were divided in three stages (column denoted St; each stage $\mathrm{N}=300$ points), according to the gs dynamics of each VPD: (A) increasing stage, (B) stationary stage and (C) decreasing stage.

Table 3. Coefficient of correlation $(\mathrm{r}, \mathrm{p}<0.001)$ between $\mathrm{CO}_{2}$ assimilation $(A)$, stomatal conductance $(g s)$, intercellular $\mathrm{CO}_{2}$ concentration $(C i)$ and transpiration $(E)$, and global connectance $(\mathrm{Cg})$ of theses parameters in the overall time series $(\mathrm{N}=2.200)$ of Citrus sinensis under three leaf-to-air vapor pressure differences $(V P D)$.

\begin{tabular}{lcccccc}
\hline$V P D$ & $A \times g S$ & $A \times C i$ & $A \times E$ & $g s \times E$ & $g s \times C i$ & $C g$ \\
\hline $1 \mathrm{kPa}$ & 0.813 & -0.872 & 0.763 & 0.994 & -0.472 & 1.379 \\
$2 \mathrm{kPa}$ & 0.989 & -0.766 & 0.989 & 0.998 & -0.690 & 2.102 \\
$3 \mathrm{kPa}$ & 0.993 & -0.878 & 0.994 & 0.999 & -0.825 & 2.413 \\
\hline
\end{tabular}

et al., 1993), in that it remains unchanged under uniform process magnification, reduction, or constant shift higher or lower. Multiple previous studies that included both theoretical analysis (Pincus, 1991; Pincus and Keefe, 1992; Pincus and Goldberger, 1994) and biological applications (Pincus et al., 1993; Pincus et al., 1996; Morrison and Newell, 1996; Pincus et al., 1996; Christen et al., 1998; Pincus et al., 1998; Bruhn et al., 2000, Souza et al., 2004) have demonstrated that these input parameters produce good statistical reproducibility for $A p E n$ for time-series of the lengths considered herein. In particular, one $A p E n$ standard deviation \pm 0.055 under very general conditions for $A p E n$ for time-series of the lengths we analyze herein. Thus $A p E n$ values that differ by 0.15 represent nearly $3 \mathrm{ApEn}$ SDs, indicating true distinction with error probability nearly $\mathrm{p}$ $=0.001$.

Because the time-series of all physiological parameters in the present experiments were markedly nonstationary,
ApEn was applied to the first-differenced gas exchange timeseries. This is a standard statistical method to stationarize time-series and is applicable to a very broad class of models (Chatfield, 1989; Willians, 1997). In order to verify the appropriateness of this data transformation, the autocorrelation coefficients of the first-differenced time-series were calculated, and representative correlogram plots are shown (figure 2).

\section{RESULTS}

Effects of VPD on gas exchange: First, for each parameter, the (overall) measurements performed throughout the day were averaged, and compared for exposure to different leafto-air vapor pressure differences. The highest $g s$ values were observed in $V P D$ of $1 \mathrm{kPa}(V P D 1)$, whereas the net photosynthesis $(A)$ and transpiration $(E)$ exhibited the highest values in $V P D$ of $2 \mathrm{kPa}(V P D 2)$ (table 1). Regardless the $V P D$ treatment, $C i$ showed a reverse relationship with $A$ (figure 1), suggesting that $\mathrm{CO}_{2}$ uptake was higher than $\mathrm{CO}_{2}$ influx, likely due to low $g s$ values, when compared with the literature (Syvertsen and Lloyd, 1994). The WUE was the highest under exposure to $V P D 1$, indicating that under this condition, a high efficiency in balance between water loss and $\mathrm{CO}_{2}$ assimilation was maintained. Increase in atmospheric demand from 1.0 to $3.0 \mathrm{kPa}$, caused reductions in $A, g s, C i$, and $W U E$ of about $25.8,50.0,17.8$ and $48.4 \%$, respectively. Nonetheless, a simple relationship between these parameters is not apparent. The decrease of $A$ cannot be seen solely as caused by stomatal control because $C i$ in $V P D$ of 3 
Table 4. Coefficient of correlation (r) of the time series, by stage, between $\mathrm{CO}_{2}$ assimilation $(A)$, stomatal conductance $(g s)$, intercellular $\mathrm{CO}_{2}$ concentration $(\mathrm{Ci})$ and transpiration $(E)$, and global connectance $(\mathrm{Cg})$ of these parameters of Citrus sinensis under three leaf-to-air vapor pressure differences $(V P D)$.

\begin{tabular}{lcllllll}
\hline$V P D$ & Stages & $A \times g s$ & $A \times C i$ & $A \times E$ & $g s \times E$ & gs $\times C i$ & $C g$ \\
\hline $1 \mathrm{kPa}$ & $\mathrm{A}$ & $0.766^{1}$ & $-0.936^{1}$ & $0.762^{1}$ & $0.993^{1}$ & $-0.568^{1}$ & 1.437 \\
& $\mathrm{~B}$ & 0.106 & $-0.809^{1}$ & -0.003 & $0.861^{1}$ & 0.173 & 0.541 \\
& $\mathrm{C}$ & $0.725^{1}$ & $-0.501^{1}$ & $0.482^{1}$ & $0.808^{1}$ & $-0.256^{1}$ & 0.675 \\
$2 \mathrm{kPa}$ & $\mathrm{A}$ & $0.986^{1}$ & $-0.927^{1}$ & $0.987^{1}$ & $0.999^{1}$ & $-0.858^{1}$ & 2.343 \\
& $\mathrm{~B}$ & 0.012 & $-0.907^{1}$ & -0.200 & $0.781^{1}$ & $0.315^{1}$ & 0.620 \\
& $\mathrm{C}$ & $0.902^{1}$ & $-0.628^{1}$ & $0.897^{1}$ & $0.996^{1}$ & $-0.235^{1}$ & 1.405 \\
$3 \mathrm{kPa}$ & $\mathrm{A}$ & $0.508^{1}$ & $-0.943^{1}$ & $0.531^{1}$ & $0.988^{1}$ & $-0.704^{1}$ & 1.269 \\
& $\mathrm{~B}$ & $0.449^{1}$ & $-0.890^{1}$ & $0.425^{1}$ & $0.946^{1}$ & -0.101 & 0.851 \\
& $\mathrm{C}$ & $0.985^{1}$ & $-0.918^{1}$ & $0.984^{1}$ & $0.999^{1}$ & $-0.840^{1}$ & 2.290 \\
\hline
\end{tabular}

*Time series were divided in three stages $(\mathrm{N}=300)$, according to gs dynamic of each $V P D$ : $(\mathrm{A})$ increasing stage, $(\mathrm{B})$ stationary stage and $(\mathrm{C})$ decreasing stage. ${ }^{1} \mathrm{p}<0.0001$.

Table 5. Approximate Entropy $(A p E n)$ of the first-differenced time series $(\mathrm{N}=2.200)$ of $\mathrm{CO}_{2}$ assimilation $(A)$, stomatal conductance $(\mathrm{gs})$, intercellular $\mathrm{CO}_{2}$ concentration $(\mathrm{Ci})$, transpiration $(E)$ and water use efficiency (WUE) of Citrus sinensis under three leaf-to-air vapor pressure differences $(V P D)$.

\begin{tabular}{lccccc}
\hline$V P D$ & $A$ & $g S$ & $C i$ & $E$ & WUE \\
\hline $1 \mathrm{kPa}$ & 0.966 & 1.622 & 1.424 & 1.506 & 1.516 \\
$2 \mathrm{kPa}$ & 1.202 & 1.687 & 1.233 & 1.595 & 1.360 \\
$3 \mathrm{kPa}$ & 1.771 & 0.990 & 1.672 & 1.602 & 1.744 \\
\hline
\end{tabular}

$\mathrm{kPa}(V P D 3)$ was $2.27 \%$ higher than in VPD2 (table 1). This result suggests that the internal $\mathrm{CO}_{2}$ concentration was not the only constraint in decreasing the rate of photosynthesis.

However, the overall results presented in table 1 do not reflect short term fluctuations due to heterogeneous and distinct sub-epochs. The large CV values calculated here (table 1) suggest an important running variation in the parameters measured; this observation, in conjunction with inspection of Figure 1, suggested a more demarcated statistical evaluation (table 2). Accordingly, we next consider the temporal variation of the parameters measured.

The fluctuation of $g s$ has been measured at short time intervals throughout the day (from 9:00 to 16:00). For several of the measurement variables under consideration ( $g s, A$, $E$ ), in the three $V P D$ conditions, three main stages may be distinguished: a first stage (A) of increasing values, followed by a second stage (B) with relative stability or mean stationarity in values, then by a third stage (C) of steady decrease in values (e.g., figure 1B for $g s$ ). The measurement variable $\mathrm{Ci}$ mirrors this evolution, although in reverse - it first decreases, then stabilizes, and finally increases (figure 1D). Thus, we separated the time-series into three successive stages, the ascending, stationary, and decreasing stages respectively, analyzing each stage separately. As observed in figure 1, the duration of each one of these stages varies according to the treatment.

The duration of each stage, as estimated from the gs evolution is indicated in figure 1. Except for water use efficiency (which is a composite parameter), all the measured parameters showed a stage transition at approximately the same time. In performing this segmented stage analysis, we can more meaningfully verify via the correlation between gs and the other parameters the level of stomatal control on gas exchange.

To implement suitable statistical comparisons, both within and across stages, we compared samples of 300 data points for each stage. The short runs $(\mathrm{N}=300)$ were sampled from the mid-section of each stage, in order to avoid possible boundary effects of the following stage. The mean values of all physiological parameters calculated within each stage confirm the tendencies previously described in figure 1 for $V P D 2$ and for $V P D$ 3, except gs in VPD1. As well, it is important to note that for VPD 1 the stage $\mathrm{C}$ duration was the shortest among the stages, interestingly with a very sharp decreasing trend for $A$. Changes in $V P D$ affected the span stages. Stage A in $V P D 1$ was 148 min longer than in $V P D 3$, while stage $\mathrm{C}$ in $V P D 3$ was 175 min longer than in $V P D 1$. Stage B (stationary) was longest in $V P D 1$, and it was progressively shortened in $V P D 2$ and $V P D 3$. The $E$ timeseries had very similar (stage) time demarcations to the $g s$ time-series. However, the decreasing stage $\mathrm{C}$ of the $A$ timeseries in the different $V P D$ s tended to commence before stage $\mathrm{C}$ of gs, markedly in VPD 1 when stage $\mathrm{C}$ of $A$ started 167 min before, when compared with the $g s$ stage $\mathrm{C}$ start (figure 


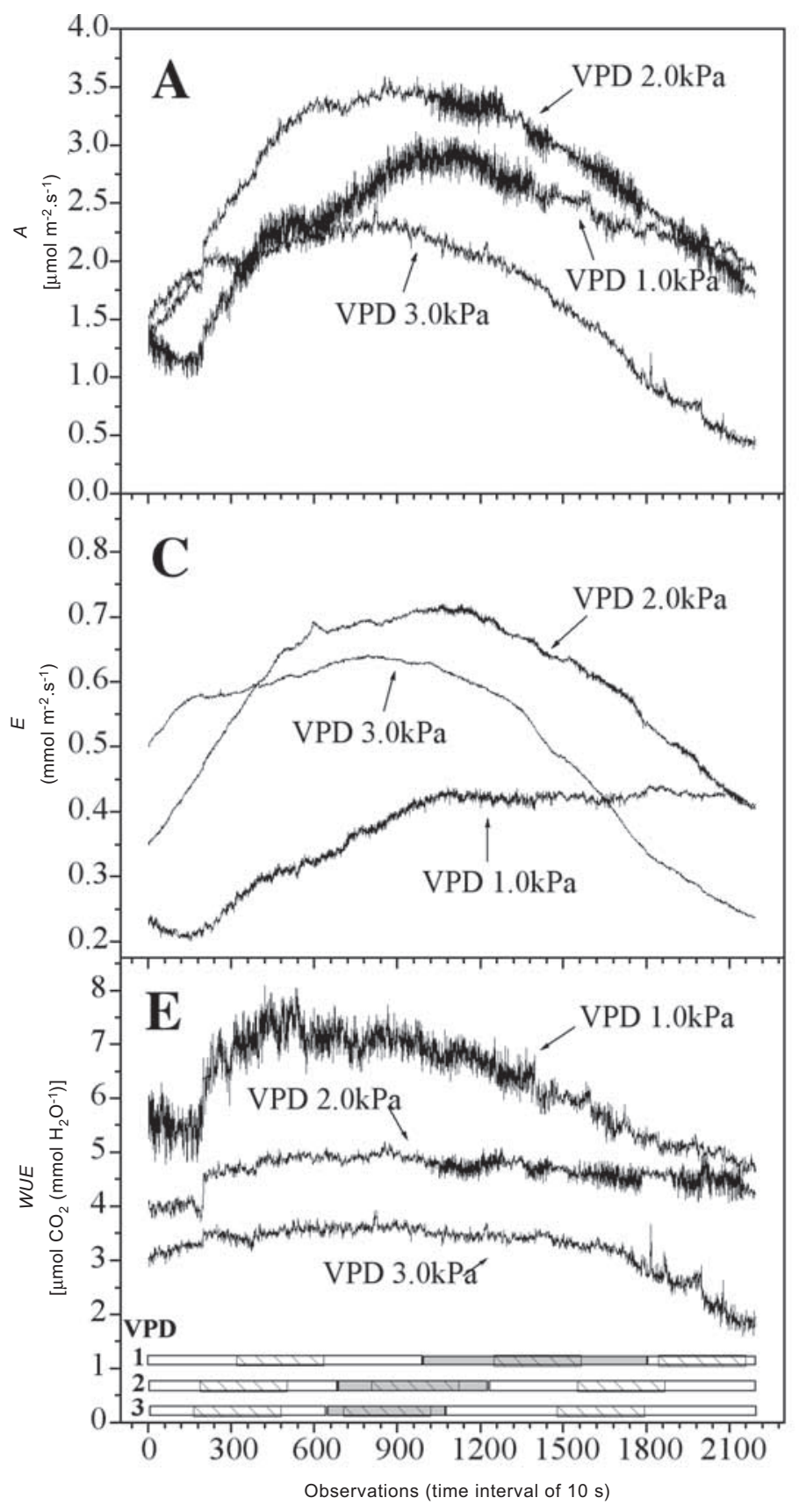

1). The stages of $C i$, although inverse in direction as noted above, were similar to A stages insofar as timing is concerned, anticipated since $C i$ is the substrate of $A$.

Thus briefly summarizing the values of the physiological parameters among the three stages in the different $V P D$ s (table 2), there was an increasing trend in $g s, A$ and $E$ values from stage A to stage B followed by a generally decreasing trend from stage B to stage C. WUE showed a decreasing trend from stage $\mathrm{A}$ to stage $\mathrm{C}$ in $V P D 1$, while in $V P D 2$ and 3 the highest $W U E$ was observed in stage B. $C i$ tended to show the highest values

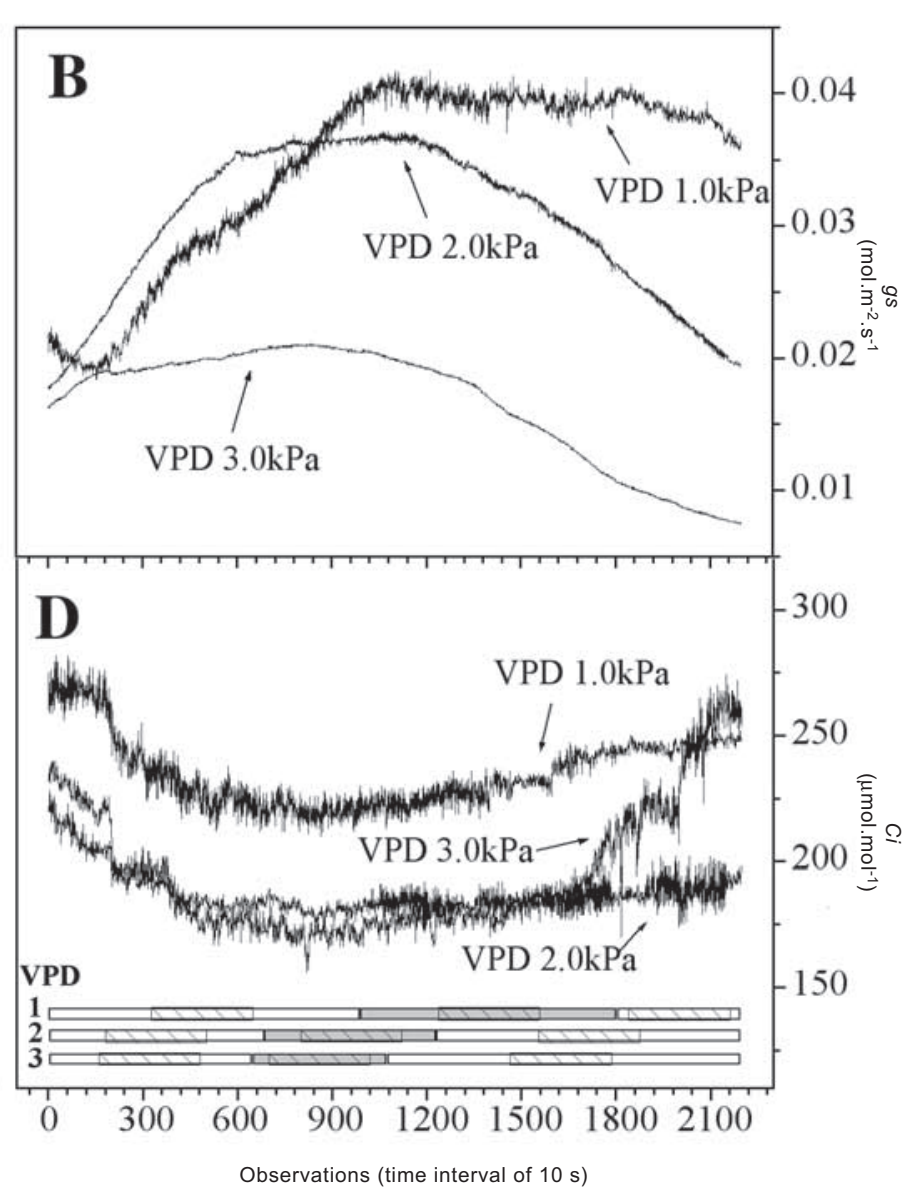

Figure 1. Time series of (a) $\mathrm{CO}_{2}$ assimilation - $A$, (b) stomatal conductance - $g s$, (c) transpiration - $E$, (d) intercellular $\mathrm{CO}_{2}$ concentration - $\mathrm{Ci}$, and (e) water use efficiency - WUE, of Citrus sinensis under three leaf-to-air vapor pressure differences $(V P D)$. Arrows indicate the VPD treatments: VPD1 (PPFD 800 $\left.\mu \mathrm{mol} . \mathrm{m}^{-2} . \mathrm{s}^{-1}, \mathrm{~T}_{\text {leaf }} 30^{\circ} \mathrm{C}, V P D 1 \mathrm{kPa}\right) ; V P D 2\left(P P F D 800 \mu \mathrm{mol} . \mathrm{m}^{-}\right.$ $\left.{ }^{2} \cdot \mathrm{s}^{-1}, \mathrm{~T}_{\text {leaf }} 30^{\circ} \mathrm{C}, V P D 2 \mathrm{kPa}\right) ; V P D 3\left(P P F D 800 \mu \mathrm{mol} \cdot \mathrm{m}^{-2} \cdot \mathrm{s}^{-1}\right.$, $\mathrm{T}_{\text {leaf }} 30^{\circ} \mathrm{C}, V P D 3 \mathrm{kPa}$ ). Observations were done with lag $10 \mathrm{~s}$, during approximately $6 \mathrm{~h}$. In the horizontal bars, showed at the bottom of the figure, are represented the three stages (A, B, and $\mathrm{C}$, as white, light-gray, and white, respectively) in each $V P D$ treatment. Sampled short runs $(\mathrm{N}=300)$ in each stage were represented in the horizontal bars by traced areas.

in stage A and the lowest ones in stage B. All differences reported here were statistically significant $(\mathrm{p}<0.05)$.

Effects of VPD on network connectance: Summarizing the overall time-series, $\mathrm{Cg}$ of the gas exchange network control showed a monotonic increase with $V P D$ increase (table 3). There was a $C g$ increase in $55.65 \%$ from $V P D 1$ to $V P D 2$, and the $C g$ from $V P D 2$ to $V P D 3$ increased by $16.25 \%$. The $g s \times E$ relationship was the most stable one across $V P D \mathrm{~s}(\mathrm{r}=$ $0.99, \mathrm{p}<0.0001$ ), due to the direct linkage between stomatal aperture and transpiration. However, such a simple link is 

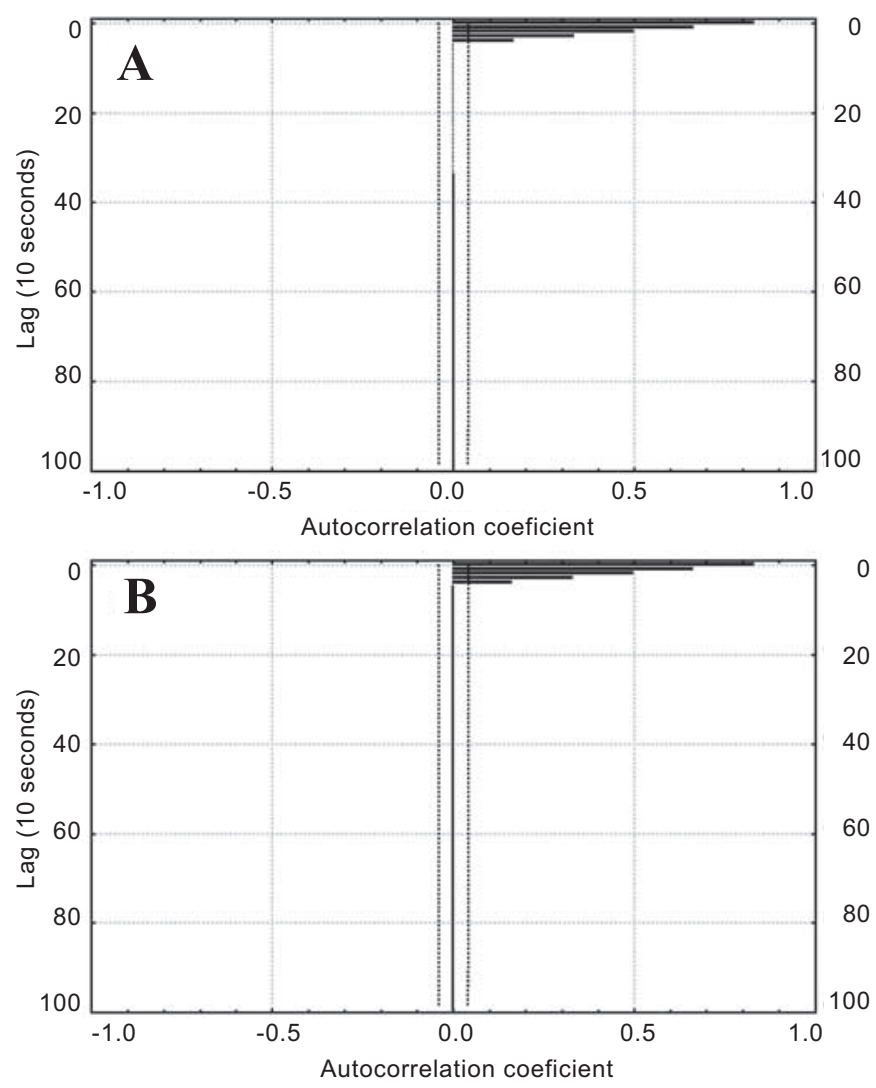

Figure 2. Correlograms of first-differenced time series for (a) $\mathrm{CO}_{2}$ assimilation and (b) transpiration time series of Citrus sinensis under leaf-to-air vapor pressure difference of $2.0 \mathrm{kPa}$.

not observed between stomatal aperture and internal $\mathrm{CO}_{2}$ content, since considerable variations in $r$ values are observed between different treatments. Internal $\mathrm{CO}_{2}$ concentration is both linked with stomatal aperture $\left(\mathrm{CO}_{2}\right.$ input $)$ and photosynthesis $\left(\mathrm{CO}_{2}\right.$ output). The relationship between $\mathrm{Ci}$ and $A$ also showed variations, but, surprisingly, the $r$ value was the lowest under VPD2 (table 3).

Considerable variations in connectance are observed between different stages. In all the treatments, a minimum value of connectance is found during the second, stationary stage. It is due mainly to the elimination of relationships between stomatal aperture $(g s$, or $E$ ) with parameters related to photosynthesis ( $A$, or even $C i$ ) (table 4 ). One may notice that recovery of high connectance on the third stage is far from being achieved for $V P D 1$, or even for $V P D 2$. In contrast, the connectance is the highest at this third stage for VPD3. This suggests that a difference in regulation processes achieved towards the third stage between VPD1 or VPD2 treatments, and VPD3. $C g$ calculations with transformed (first-differenced) data were performed showing similar trends between stages in relation to $C g$ calculations from original data (data not shown). Thus, in order to allow direct comparison to a number of previous studies, which have either always or usually also studied only the raw (nontransformed) data, we have retained the original $\mathrm{Cg}$ calculations in the text.

Effects of VPD on gas exchange dynamics: Although the $V P D$ effects on gas exchange dynamics have exhibited differences in some experimental sets, the data shown below are representative of the general changes in gas exchange dynamics evaluated by $A p E n$ calculations.

Despite the constant environmental conditions during measurements, the overall time-series of all physiological parameters were typically nonstationary (figure 1). Thus, $A p E n$ was applied to first-differenced (D-1) gas exchange time-series. As observed in the correlograms of these D-1 time-series, the autocorrelation coefficients consistently showed a random-like fluctuation around a value of zero with time (lag), indicating that the first-difference was suitable in order to remove the nonstationary factors, i.e., approximately mean stationary. Furthermore, the correlation coefficients were practically zero for time-lags longer than about 50-60 s, showing the existence of the finite limit for significant auto-correlation. Correlograms of representative first-differenced time-series $A$ (D-1) and $E$ (D-1) in VPD2 are shown in figure 2. Similar results were obtained for timeseries in $V P D 1$ and $V P D 3$.

The highest $A p E n$ values in the overall time-series were typically found in $V P D 3$, except for the gs time-series where the lowest $A p E n$ value was found in $V P D 3$. ApEn value of $A$ time-series generally showed an increasing trend with increasing VPD. $C i$ and WUE time-series showed the lowest $A p E n$ in VPD2, and the highest ones were found in $V P D 3$. $A p E n$ of $E$ time-series were similar in the different $V P D$ s, although a slight increasing trend from $V P D 1$ to 3 was observed (table 5). The ApEn results suggest that $A$ was the most sensitive physiological parameter in order to capture changes in temporal dynamics.

\section{DISCUSSION}

The effects of increasing $V P D$ on $A$ and $E$ have been associated with changes in $g s$ (Khairi and Hall, 1976; Cowan, 1977; Farquhar and Sharkey, 1982). The partial stomatal closing in citrus in response to increasing $V P D$ could be an evolutive adaptation to maintain the plant water status, mainly in regions of high atmospheric demand (Quick et al., 1992; Syvertsen and Lloyd, 1994). The VPD value that 
caused stomatal closing in our study was $3.0 \mathrm{kPa}$; in other studies, these values were around $1.5 \mathrm{kPa}$ (Sinclair and Allen Jr., 1982), $2.0 \mathrm{kPa}$ (Khairi and Hall, 1976) and $3.0 \mathrm{kPa}$ (Medina et al., 1998 and 1999).

However, as this study was carried out without water constraints with well-watered plants, a rigorous stomatal control of $A$ and $E$ was not observed, although $g s$ responses to $V P D$, such as the accentuated decrease in $V P D 3$, have been in agreement with natural $C$. sinensis responses to high atmospheric demands (Khairi and Hall, 1976, Syvertsen and Lloyd, 1994).

In spite of $g s$ decreasing in VPD2 (12\%), $E$ increased in $60 \%$ (table 1). This effect in $E$ may be understood by a straightforward relation with a higher atmospheric demand. From $V P D 2$ to $V P D 3$ gs decreased by $43 \%$ while $E$ decreased by only $14 \%$ (table 1 ). This relative stability of $E$ is probably explained by excessive stomatal opening, because of the wellwatered condition, in relation to the low atmospheric demand in $V P D 1$, furthermore an increasing in cuticular transpiration importance could be, in part, associated to an increase in $V P D$.

In the $V P D 3, A$ decreased by $39 \%$ compared with $V P D 2$. Although gs was low (just $0.017 \mathrm{~mol} \cdot \mathrm{m}^{-2} \cdot \mathrm{s}^{-1}$ ) in $V P D 3$, it was not the cause of $A$ reduction because $C i$ was similar to $V P D 2$ where $A$ showed the highest values. This phenomenon is explained in part by stomatal patchiness resulting in overestimation of $\mathrm{Ci}$ (Cheeseman, 1991; Mott and Buckley, 1998; Cornic, 2000). Furthermore, these results could suggest that a biochemical limitation of $\mathrm{CO}_{2}$ assimilation must be occurring, once $\mathrm{Ci}$ may be not limited. This endogenous decrease in $A$ could be understood as an anticipated response (feedforward mechanism) to an eventual stomatal closing, promoted by a high $V P D$ which could cause leaf dehydration and lead to maintenance of $\mathrm{CO}_{2}$ storage for further photosynthesis support under stressed conditions (Raschke, 1987; Nobel, 1999; Luan, 2002).

$W U E$ results support the lack of stomatal control of gas exchange because increasing $V P D$ caused $W U E$ decrease. In general, high $V P D$ s under field conditions with water constraints are associated with $W U E$ increasing (Larcher, 1995)

The control of stomatal movements is achieved by complex relationships among hormonal (ABA) and ionic balance, water movement and anatomical organization of the plant in response to environmental stimulation (Farquhar and Sharkey, 1982; Zieger et al., 1987; Jones, 1998). The regulation of photosynthesis is affected by stomatal behavior, and depends on an intricate metabolic network (Z-scheme,
Calvin-Benson Cycle) linked to source-sink dynamics (Farquhar et al., 1980; Farquhar and Sharkey, 1982; Jones, 1998). Probably, not only does gs affect both $A$ and $E$, but these have a range of feedback effects on gs, either directly or indirectly. In addition, environmental factors may also affect any of these variables and the gain of the feedback loops (Jones, 1998). Therefore, the network findings in the present study, likely are not representing all agents involved in a "real" network.

Thus, we have two modes of regulation of gas exchange. The first is a double recontrol, so that $A$ and $E$ influence $g s$ and $g s$ also influences $A$ and $E$, i.e., an autoregulation process. The first level of regulation in the relationship between $A$ and $g s$ may be doubled by another (heteroregulation), in which both $g s$ and $A$ are controlled by a third parameter.

The results showed changes in CV (table 1) in all parameters in the different $V P D$ conditions. This variability indicated by $\mathrm{CV}$ values in the data settings may have a biological significance (Trewavas, 1986; Green, 1996; Erdei et al., 1998; Amzallag, 1999 and 2001; Hütt and Lüttge, 2002). Networks with a greater redundancy degree or degeneration, facilitate the maintenance of biological system homeostasis when disturbed by external factors (Trewavas, 1986; Edelman and Gally, 2001). For the overall series, the $\mathrm{CV}$ values were modified in parallel, suggesting that physiological parameters measured were probably linked, possibly in a star-like pattern, indicating a typical stress response (Amzallag, 2001). It is important to emphasize that under water restriction $g s$ assumes a central role in the network of gas exchange modulation (Chaves, 1991; Jones, 1998). In a broad sense, a qualitatively similar pattern of organization is also observed between different stages in each VPD. As noted by Amzallag (2001), variability is not necessarily an undesirable experiment artifact. Rather, it is the transformation of the inherent noise by the biological system that provides information about its pattern of regulation.

When we consider the whole time-series, the increase in $C g$ with increasing $V P D$ showed a continuous adaptive pattern of gas exchange regulation (Amzallag, 2001). However, the reduction in $C g$ at stage $\mathrm{B}$ in each time-series indicates an intrinsic non-monotonicity or discontinuity of the regulation pattern. The higher values of $C g$ in stages $\mathrm{A}$ and $\mathrm{C}$ (both nonstationary) in relation to stage $\mathrm{B}$ showed a higher gas exchange control, which could be related to the phenomenon of circadian cycle of aperture and stomatal closing observed even under constant environmental conditions (Kriedemann, 1968; Barrs, 1971; Hennessey and Field, 1991; Webb, 1998). 
This phenomenon reinforces the endogenous or self-organized regulatory pattern of plants, which promotes a certain degree of autonomy in relation to the environment. Conversely, since higher levels of connectance are related to higher system stability (assumptions $1-4$ in Introduction), the lowest values of $C g$ at stage B, independently of $V P D$, indicates that plants may be more susceptible to external stimuli at this period (Souza et al., 2004c), such as factors that cause the midday depression observed in citrus under field conditions (Brakke and Allen Jr., 1995).

In the time-series analyzed, the VPD 3 treatment induced the highest $A p E n$ values, except for $g s$. There was a general tendency towards increasing time-series irregularity from $V P D 1$ to $V P D 3$, but $A p E n$ values of $V P D 2$ showed an accentuated variation in each physiological parameter evaluated. This suggests that $V P D 2$ was a transitory condition between a low atmospheric demand (VPD1) and a high one (VPD3). We propose that an increase in the control of the gas exchange regulation, such as observed in VPD3 (table 3 ), could afford a higher complexity of gas input and output dynamics through finer tuning, optimizing the gas exchange responses under higher atmospheric demand, accordingly to assumption 5 in the Introduction. The highest regularity of $g s$ (indicated by the lowest $A p E n$ values) in $V P D 3$ could possibly be explained by the partial closing of the stomata, which could constrain their open-close movement limiting the range of aperture variation of stomatal pores (Nobel, 1999). Nonetheless, a similar finding was not seen for the $A$ dynamic at $V P D 3$, even given the low values of $A$ in this condition, possibly due to the fact of $A$ has been affected not only by the biophysical relations of gas exchange, but also because it is dependent on a complex enzymatic system of $\mathrm{CO}_{2}$ carboxylation. Krempasky et al. (1993) observed different temporal dynamics in photosynthetic system ranging from periodic to chaotic in response to external stimuli. Thus, we suggest that photosynthesis may be the more suitable parameter to evaluate changes in temporal dynamics of plants under different environmental conditions.

Our results indicated that variations in VPD affected the temporal dynamic of gas exchange. However, because this is the first study that uses $A p E n$ as a measurement of plant physiology regularity, some caution should be taken in relation to the interpretation of results. Future studies are necessary to validate functional correlates between alteration in patterns or dynamics and resultant interactions between plant status and environmental surroundings. Nonetheless, changes in ApEn have been shown to correlate with physiological and pathophysiological change in numerous and diverse settings (Fleisher et al., 1993; Pincus et al., 1993; Morrison and Newell, 1996; Pincus et al., 1996; Christen et al., 1998; Bruhn et al., 2000), which suggest that its use in plant research could be of considerable scientific utility when used to help to better understand plant physiological responses under stress conditions.

Our study showed that detailed quantitative analysis in plant biology experiments, particularly evaluations of temporal dynamics of physiological data, may be a more subtle problem than was generally previously considered. Because of general system nonlinearities and complex configurations and interactions, biological systems may be very sensitive to small changes in experimental conditions; thus we could a priori expect a broad range of responses to qualitatively similar stimuli. However, the results showed that citrus responses to $V P D$ changes were coordinated by alterations in network connectance, which showed evidence of redundant modulation as indicated by changes in $\mathrm{CV}$ values (Amzallag, 2001).

Moreover, $V P D$ changes affected the endogenous dynamics of gas exchange by alterations of stage lengths, and $A p E n$ values (complexity of the time-series). These experiments in constant environment highlighted the selforganized mechanisms that drive the gas exchange process, indicating interesting biological endogenous modes of modulation and complex dynamics. Furthermore, the observation of different levels of network connectance throughout the day, such as the lower connectance in stage $\mathrm{B}$, could be useful to crop management (e.g. to determine irrigation periods) or to scientific experimental designs (e.g. choice of the different periods of sensitivity to external stimuli).

Acknowledgments: The authors are grateful to Dr. G. N. Amzallag for editorial comments and insightful discussions. To Dr. Ricardo F. de Oliveira for technical support. G.M.S. and R.V.R. are grateful to FAPESP (Fundação de Amparo à Pesquisa do Estado de São Paulo) for fellowships granted.

\section{Appendix}

Mathematical definition of ApEn - Given $\mathrm{N}$ data points $\mathrm{u}(1), \mathrm{u}(2), \ldots \mathrm{u}(\mathrm{N})$, two input parameters, $\mathrm{m}$ and $\mathrm{r}$, must be fixed to compute $A p E n$ (denoted precisely by $A p E n(\mathrm{~m}, \mathrm{r}, \mathrm{N})$ ). To define $A p E n$, first form vector-sequences $\mathrm{x}(1)$ through $\mathrm{x}(\mathrm{N}-\mathrm{m}+1)$ from the $\{\mathrm{u}(\mathrm{i})\}$, defined by $\mathrm{x}(\mathrm{i})=[\mathrm{u}(\mathrm{i}), \ldots, \mathrm{u}(\mathrm{i}+\mathrm{m}-$ 1)]. These vectors represent $m$ consecutive $u$ - values, 
commencing with the $i^{\text {th }}$ point. Define the distance $d[x(i), x(j)]$ between vectors $x(i)$ and $x(j)$ as the maximum difference in their respective scalar components. Use the sequence $\mathrm{x}(1)$, $\mathrm{x}(2), \ldots \mathrm{x}(\mathrm{N}-\mathrm{m}+1)$ to construct, for each $\mathrm{i} \leq \mathrm{N}-\mathrm{m}+1, C i \mathrm{~m}(\mathrm{r})=$ (number of $x(j)$ such that $d[x(i), x(j)] \leq r) /(N-m+1)$. The $C i^{\mathrm{m}}(\mathrm{r})$ 's measure within a tolerance $\mathrm{r}$ the regularity, or frequency, of patterns similar to a given pattern of window length $\mathrm{m}$. Next, define $\Phi^{\mathrm{m}}(\mathrm{r})$ as the average value of $\ln$ $C i^{\mathrm{m}}(\mathrm{r})$, where $\ln$ is the natural logarithm. We define approximate entropy by $A p E n(\mathrm{~m}, \mathrm{r}, \mathrm{N})=\Phi^{\mathrm{m}}(\mathrm{r})-\Phi^{\mathrm{m}+1}(\mathrm{r})$.

\section{REFERENCES}

Amzallag GN (1999) Plant evolution: toward an adaptive theory. In: Lerner, H.R. (ed), Plant responses to environmental stresses: from phytohormones to genome reorganization, $\mathrm{pp}$. 171-245. Marcel Dekker, New York.

Amzallag GN (2001) Data analysis in plant physiology: are we missing the reality? Plant Cell Environ. 24:881-890.

Barrs HD (1971) Cyclic variations in stomatal aperture, transpiration, and leaf water potential under constant environmental conditions. Annu. Rev. Plant Physiol. 22:223-236.

Brakke M, Allen Jr LH (1995) Gas exchange of Citrus seedlings at different temperatures, vapor-pressure deficits, and soil water contents. J. Am. Soc. Hort. Sci. 120:497-504.

Bruhn J, Ropcke H, Rehberg B, Bouillon T, Hoeft A (2000) Electroencephalogram approximate entropy correctly classifies the occurrence of burst suppression pattern as increasing anesthetic drug effect. Anesthesiology 93:981-985.

Buckley TN, Farquhar GD, Mott K (1997) Qualitative effects of patchy stomatal conductance distribution features on gasexchange calculations. Plant Cell Environ. 20:867-880.

Chatfield C (1989) The analysis of time series: an introduction. pp.42-43, 59-60. Chapman \& Hall, London.

Chaves MM (1991) Effects of water deficits on carbon assimilation. J. Exp. Bot. 42:1-16.

Cheeseman JM (1991) PATCHY: simulating and visualizing the effects of stomatal patchiness on photosynthetic $\mathrm{CO}_{2}$ exchange studies. Plant Cell Environ. 14:593-599.

Christen JA, Torres J-L, Barrera J (1998) A statistical feature of genetic sequences. Biometrical J. 40:855-863.

Cornic G (2000) Drought stress inhibits photosynthesis by decreasing stomatal aperture - not by affecting ATP synthesis. Trends Plant Sci. 5:183-221.

Cowan IR (1977) Stomatal behaviour and environment. Adv. Bot. Res. 4:117-228.

Edelman GM, Gally JA (2001) Degeneracy and complexity in biological systems. Proc. Natl. Acad. Sci. USA 98:1376313768.

Erdei L, Szeglets Z, Barabás KN, Pestenácz A, Fülöp K, Kalmár L, Kovács A, Tóth B, Dér A (1998) Environmental stress and the biological clock in plants: changes of rhythmic behaviour of carbohydrates, antioxidant enzymes and stomatal resistance by salinity. J. Plant Physiol. 152:265-271.
Farquhar GD, von Caemmerer S, Berry JA(1980) A biochemical model of photosynthetic $\mathrm{CO}_{2}$ assimilation in leaves of $\mathrm{C}_{3}$ species. Planta 149:78-90.

Farquhar GD, Sharkey TD (1982) Stomatal conductance and photosynthesis. Annu. Rev. Plant Physiol. 33:317-345.

Fleisher LA, Pincus SM, Rosenbaum SH (1993) Approximate entropy of heart rate as a correlate of postoperative ventricular dysfunction. Anesthesiology 78:683-692.

Green PB (1996) Transductions to generate plant form and pattern: an essay on cause and effect. Ann. Bot. 78:269-281.

Haefner JW, Buckley TN, Mott KA (1997) A spatially explicit model of patchy stomatal responses to humidity. Plant Cell Environ. 20:1087-1097.

Hennessey TL, Field CB (1991) Circadian rhythms in photosynthesis. Plant Physiol. 96:831-836.

Hütt M-Th, Lüttge U (2002) Nonlinear dynamics as a tool for modeling in plant physiology. Plant Biol. 4:281-297.

Jones H (1998) Stomatal control of photosynthesis and transpiration. J. Exp. Bot. 49:387-398.

Khairi MMA, Hall AE (1976) Temperature and humidity effects on net photosynthesis and transpiration of citrus. Physiol. Plant. 36:29-34.

Krempasky J, Smrcinova M, Ballo P (1993) Periodicity and chaos in a photosynthetic system. Photosynth. Res. 37:159164.

Kriedemann PE (1968) Some photosynthetic characteristics of citrus leaves. Aust. J. Biol. Sci. 21:895-905.

Larcher W (1995) Physiological plant ecology. p.506. Springer, Berlin - Heidelberg.

Levy Y (1980) Effect of evaporative demand on water relations of Citrus limon. Ann. Bot. 46:695-700.

Luan S (2002) Signalling drought in guard cells. Plant Cell Environ. 25:229-238.

Medina CL, Machado EC, Pinto JM (1998) Fotossíntese de laranjeira 'Valencia' enxertada sobre quatro porta-enxertos e submetida à deficiência hídrica. Bragantia 57:1-14.

Medina CL, Machado EC, Gomes MMA (1999) Condutância estomática, transpiração e fotossíntese em laranjeira 'Valência' sob deficiência hídrica. Braz. J. Plant Physiol. 11:29-34.

Møller AC, Hauser MJB, Olsen LF (1998) Oscilations in peroxidase-catalyzed reactions and their potential function in vivo. Biophys. Chem. 72:63-72.

Morrison S, Newell KM (1996) Inter- and intra-limb coordination in arm tremor. Exp. Brain Res. 110:455-464.

Mott KA, Buckley TN (1998) Stomatal heterogeneity. J. Exp. Bot. 49:407-417.

Nicolis G, Prigogine I (1977) Self-organization in nonequilibrium systems. John Wiley \& Sons, New York.

Nobel PS (1999) Physicochemical and environmental plant physiology. p.473. Academic Press, San Diego.

Pearcy RW, Ehleringer J, Mooney H, Rundel PW (1989) Plant physiological ecology: field methods and instrumentation. p.457. Chapman \& Hall, New York.

Pincus SM (1991) Approximate entropy as a measure of system complexity. Proc. Natl. Acad. Sci. USA 88:2297-2301.

Pincus SM, Huang WM (1992) Approximate entropy: statistical properties and applications. Commun. Statist. - Theory Meth. 21:3061-3077. 
Pincus SM, Keefe DL (1992) Quantification of hormone pulsatility via an approximate entropy algorithm. Am. J. Physiol. 262:E741-E754.

Pincus SM, Cummins TR, Haddad GG (1993) Heart rate control in normal and aborted SIDS infants. Am. J. Physiol. 264:R638-R646.

Pincus SM (1994) Greater signal regularity may indicate increased system isolation. Math. Biosci. 122:161-181.

Pincus SM, Goldberger AL (1994) Physiological time-series analysis: What does regularity quantify? Am. J. Physiol. 266:H1643-H1656.

Pincus SM, Gevers E, Robinson ICAF, van den Berg G, Roelfsema F, Hartman ML, Veldhuis JD (1996) Females secrete growth hormone with more process irregularity than males in both human and rat. Am. J. Physiol. 270:E107-E115.

Pincus SM, Mulligan T, Iranmanesh A, Gheorghiu S, Godschalk M, Veldhuis JD (1996) Older males secrete luteinizing hormone (LH) and testosterone more irregularly, and jointly more asynchronously, than younger males. Proc. Natl. Acad. Sci. USA 93:14100-14105.

Pincus SM, Singer BH (1996) Randomness and degrees of irregularity. Proc. Natl. Acad. Sci. USA 93:2083-2088.

Pincus SM, Kalman RE (1997) Not all (possibly) "random" sequences are created equal. Proc. Natl. Acad. Sci. USA 94:3513-3518

Pincus SM, Padmanabhan V, Lemon W, Randolph J, Midgley AR (1998) FSH is secreted more irregularly than LH in both human and sheep. J. Clin. Invest. 101:1318-1324.

Pincus SM, Singer BH (1998) A recipe for randomness. Proc. Natl. Acad. Sci. USA 95:10367-10372.

Pincus SM (2000) Irregularity and asynchrony in biologic network signals. In: Johnson ML, Brand L (eds), Methods in enzymology: numerical computer methods, Part C, v. 321, pp. 149-182. Academic Press, San Diego.

Quick WP, Chaves M.M, Wendler R, David M, Rodrigues ML, Passarinho JA, Pereira JS, Adcock MD, Leegood RC, Stitt M(1992) The effect of water stress on photosynthetic carbon metabolism in four species grown under field conditions. Plant Cell Environ. 15:25-35.

Raschke K (1987) Action of abscisic acid on guard cells. In: Zeiger, E., Farquhar, G.D. and Cowan, I.R. (eds), Stomatal function, pp.253-279. Stanford University Press, Stanford.

Sinclair TR, Allen Jr LH (1982) Carbon dioxide and water vapour exchange of leaves on field-grown citrus trees. J. Exp. Bot. 33:1166-1175.

Souza GM, Ribeiro RV, Santos MG, Ribeiro HL, Oliveira RF (2004a) Approximate entropy as a measure of complexity in sap flow temporal dynamics of two tropical tree species under water deficit. An. Acad. Bras. Cienc. 76:625-630.

Souza GM, Oliveira RF, Cardoso VJM (2004b) Temporal dynamics of stomatal conductance of plants under water deficit: can homeostasis be improved by more complex dynamics? Braz. Arch. Biol. Technol 47:423-431.

Souza GM, Ribeiro RV, Santos MG, Ribeiro HL, Oliveira RF (2004c) Functional groups of forest succession as dissipative structures: an applied study. Braz. J. Biol. 64:709-720.

Syvertsen JP, Lloyd JJ (1994) Citrus. In: Schaffer B, Andersen PC (eds), Handbook of environmental physiology of fruit crops - subtropical and tropical crops, pp.65-100. CRC Press, Boca Raton.

Trewavas A (1986) Understanding the control of plant development and the role of growth substances. Aust. J. Plant Physiol. 13:447-457.

Van Voris VP, O’Neil RV (1980) Functional complexity and ecosystem stability. Ecology 61:1352-1360.

Veste M, Ben-Gal A, Shani U (2000) Impact of thermal stress and high VPD on gas exchange and chlorophyll fluorescence of Citrus grandis under desert conditions. Acta Hort. 531:143-149.

Webb A.R (1998) Stomatal rhythms. In: Lumsden PJ, Millar AJ (eds) Biological rhythms and photoperiodism in plants, pp.6980. Bios Scientific Publishers, Oxford.

Willians GP (1997) Chaos theory tamed. p.499. Joseph Henry Press, Washington D.C.

Zeiger E, Farquhar GD, Cowan. IR (1987) Stomatal function. p.503. Stanford University Press, Stanford 